
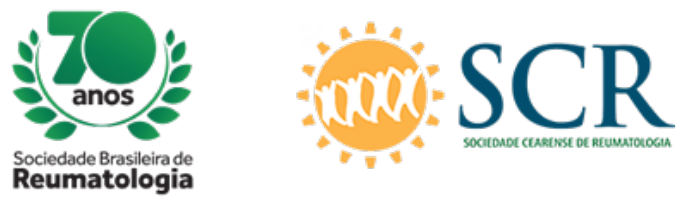

\title{
THE SEROCONVERSION RATE OF THE YELLOW FEVER VACCINE IS LOWER IN PATIENTS VACCINATED INADVERTENTLY
}

Ketty Lysie Libardi Lira Machado (Universidade Federal do Espírito Santo, Vitória, ES, Brasil), Valéria Valim (Universidade Federal do Espírito Santo, Vitória, ES, Brasil), Sheila Maria Barbosa de Lima (Instituto de Tecnologia em Imunobiológicos (BIOMANGUINHOS), FIOCRUS, Rio de Janeiro, RJ, Brasil), Ana Carolina Campi Azevedo (Instituto de Tecnologia em Imunobiológicos (BIOMANGUINHOS), FIOCRUZ, Rio de Janeiro, RJ, Brasil), Andréa Teixeira Carvalho (Centro de Pesquisa René Rachou, FIOCRUZ, Belo Horizonte, MG, Brasil), Lidia Balarini (Universidade Federal do Espírito Santo, Vitória, ES Brasil), Samira Tatiyama Miyamoto (Universidade Federal do Espírito Santo, Vitória, ES, Brasil), Ana Lidia SIlva de Souza (Universidade Federal do Espírito Santo, Vitória, ES, Brasil), Priscila Costa Martins Rocha (Universidade Federal do Espírito Santo, Vitória, ES, Brasil), Thays Zanon (Secretaria de Estado da Saúde do Espírito Santo, Vitória, ES, Brasil), Erica Vieira Serrano (Universidade Federal do Espírito Santo, Vitória, ES, Brasil), Rubemn Horst Duque (Universidade Federal do Espírito Santo, Vitória, ES, Brasil), Maria Bernadete Renoldi de Oliveira Gavi (Universidade Federal do Espírito Santo, Vitória, ES, Brasil), Valquiria Garcia Dinis (Universidade Federal do Espirito Santo, Vitória, ES, Brasil), Larissa Carvalho Caser (Universidade Federal do Espirito Santo, Vitória, ES, Brasil), Arthur Dalmaso (Universidade Federal do Espírito Santo, Vitória, ES, Brasil), Ana Paula Burian (Secretaria de Saúde do Estado do Espírito Santo, Vitória, ES, Brasil), Lauro Ferreira da Silva Pinto (Santa Casa de Misericórdia de Vitória, Vitória, ES, Brasil), Elizandra Polito (Secretaria de estado da Saúde do Espírito Santo, Vitória, ES, Brasil), Thalles Brandão Clemente (Universidade Federal do Espírito Santo, Vitória, ES, Brasil), Enan Sales Magalhães

(Universidade Federal do Espírito Santo, Vitória, ES, Brasil), Luiza Correa Rodrigues (Universidade Federal do Espírito Santo, Vitória, ES, Brasil), Fernanda Morello (Universidade Federal do Espírito Santo, Vitória, ES, Brasil), Karine Gadioli Oliveira (Universidade Federal do Espírito Santo, Vitória, ES, Brasil), Marcela Marçal Thebit (Universidade Federal do Espírito Santo, Vitória, ES, Brasil), Maria de Fátima Bissoli (Universidade Federal do Espírito Santo, Vitória, ES, Brasil), Sônia Alves Gouvêa (Universidade Federal do Espírito Santo, Vitória, ES, Brasil), Letícia Resende Brandão (Secretaria de estado da Saúde do Espírito Santo, Vitória, ES, Brasil), Luciana Dalva de Moura (Universidade Federal do Espírito Santo, Vitória, ES, Brasil), Lorena Baptista Almeida (Universidade Federal do Espírito Santo, Vitória, ES, Brasil),

Raissa Hirle Krettle (Universidade Federal do Espírito Santo, Vitória, ES, Brasil), Juliana Taube (Universidade Federal do Espírito Santo, Vitória, ES, Brasil), João Gabriel Fragoso (Universidade Federal do Espirito Santo, Vitória, ES, Brasil), Franco Salume (Universidade Federal do Espírito Santo, Vitória, ES, Brasil), Franco Salume (Universidade Federal do Espírito Santo, Vitória, ES, Brasil), Olindo Assis (Centro de Pesquisas René Rachou, FIOCRUZ, Belo Horizonte, MG, Brasil)

\section{BACKGROUND}

The yellow fever vaccine contains a live attenuated virus of high immunogenicity and offers prolonged protection against yellow fever and it is generally safe in immunocompetent patients. However, in individuals with rheumatic diseases, it is necessary to evaluate the patient, avoiding vaccinations inadvertently. In addition, drug use and disease's activities may influence in vaccine's seroconversion.

\section{MATERIALS AND METHODS}

Retrospective observational study evaluating 37 patients after 30 days of vaccination, being the diagnoses: Rheumatoid Arthritis (RA) ( $n=15)$, Sjögren's Syndrome (SS) ( $n=10)$, Ankylosing Spondylitis (AS) $(n=8)$, Systemic Lupus Erythematosous (SLE) $(n=1)$, Still Disease (SD) $(n=1)$, Mixed Connective Tissue Disease (MCTD) ( $n=01)$ and Systemic Vasculitis (SV) $(n=01)$. Viremia (CRP) and plaque reduction neutralization test (PRNT) were measured in D28 after vaccine. Adverse events were registered and 
adequate statistical analysis was performed. All tests considering a significant $p$-value $<0.05$. The PRNT was expressed in GeoMean title.

\section{RESULTS}

18 of the evaluated patients were vaccinated inadvertently (48.6\%), of which $13(72.2 \%)$ were on immunobiological use [(Infliximabe (6), Adalimumabe (1), Abatacepte (2), Tocilizumabe (4)] and 5 (27.7\%) on DMARDs use. There were no AE related in the inadvertent group. In the warned group $(n=19 ; 51.4 \%)$, 4 were on immunobiological use and only 5 were on DMARDs use. Myalgia and fatigue (SS without medication), myalgia (RA using methotrexate $7.5 \mathrm{mg} /$ week), and arthralgia and skin rash (SS using prednisone $5 \mathrm{mg}$ / day) were observed in this group. A patient with RA using methotrexate $15 \mathrm{mg} /$ week and leflunomide $20 \mathrm{mg}$ / day was diagnosed with endocarditis after 4 weeks of vaccination, but she already had mitral stenosis and we can not assign this event to the vaccine. The laboratory analysis was performed in 27 patients, 10 inadvertent and 17 warned, diagnosed with RA ( $n=7,2$ warned and 5 inadvertent), SS ( $n=9$, all warned), spondylarteritis ( $n=6,3$ warned and 3 inadvertent), Lupus ( $n=1$; Still's disease ( $n=1$, inadvertent), MCTD ( $n=1$, warned) and Takayasu's arteritis $(n=1$, inadvertent). Seropositivity was significantly lower in the inadvertent group compared to warned group (64\% vs. $94 \%$, $p=0.03)$. The PRNT title in D28 was 247 warned and 91 inadvertent, $p=0.08$.

\section{CONCLUSION}

No serious adverse events have been observed even in patients who have been vaccinated inadvertently. The seroconversion rate was lower in the group of inadvertently vaccinated, emphasizing the importance of medical guidance. 